\title{
Causes of visual disability among Central Africans with diabetes mellitus
}

\author{
Mvitu Muaka $\mathrm{M}^{1}$, *Longo-Mbenza $\mathrm{B}^{2}$
}

1. Department of Ophthalmology, University of Kinshasa, DRC

2. Walter Sisulu University, Faculty of Health Sciences, Mthatha, Eastern Cap, South Africa

\begin{abstract}
Background: Diabetic Retinopathy (DR) remains a common and one of the major causes of blindness in the developed and western societies. The same situation is shown in emerging economic areas (5,6). In sub-Saharan Africa (SSA) however, the issues of visual disability due to diabetes mellitus (DM) are overshadowed by the presence of the prevalent and common nutritional deficiency diseases and eye infections

Objective: This clinic-based study was conducted to determine whether diabetic retinopathy is independently related to visual disability in black patients with diabetes mellitus (DM) from Kinshasa, Congo.

Methods: A total of 299 urban patients with DM and low income including 108 cases of visual disability and matched for time admission and DM type to 191 controls, were assessed. Demographic, clinical, and ophthalmic data were assessed using univariate and multivariate analyses.

Results: Age $\geq 60$ years, female sex, presence of diabetic retinopathy (DR), proliferative DR, shorter DM duration, glaucoma, macular oedema, diabetic nephropathy were the univariate risk factors of visual disability. Using logistic regression model, visual disability was significantly associated with female sex and diabetic retinopathy.

Conclusion: The risk of visual disability is 4 times higher in patients with diabetic retinopathy and 2 times higher in females with DM. Therefore, to prevent further increase of visual disability, the Congolese Ministry of Health should prioritize the eye care in patients with DM.
\end{abstract}

Keywords: Visual disability, diabetic retinopathy, females, risk factors, Central Africa

African Health Sciences 2012; 12(2): 193 - 197 http://dx.doi.org/10.4314/ahs.v12i2.18

\section{Introduction}

The burden of visual disability including blindness and visual impairment or low vision ${ }^{1}$ is well established worldwide. Diabetic retinopathy (DR) remains a common and one of the major causes of blindness in the developed and western societies ${ }^{2,3}$. Visual disability affects an estimated 3.4 million US adults aged $\geq 40$ years and it is caused by DR and age - related eye diseases (cataracts, macular degeneration and glaucoma) ${ }^{4}$. The same situation is shown in emerging economic areas ${ }^{5,6}$.

In sub-Saharan Africa (SSA) however, the issues of visual disability due to Diabetes Mellitus (DM) are overshadowed by the presence of the prevalent and common nutritional deficiency diseases and eye infections such as vitamin A deficiency,

\footnotetext{
*Correspondence author:

Professor Longo-Mbenza Benjamin

Champion Research Professor

Walter Sisulu University

Faculty of Health Sciences

Private Bag X1, Mthatha 5117

Eastern Cape, South Africa

Tel +27732822843

Email : longombenza@gmail.com
}

trachoma, onchocerciasis and other conditions ${ }^{7}$. For this reason, we have undertaken a recent study, which showed an unexpected high frequency of visual disability estimated to be $36 \%$ among Congolese patients with $\mathrm{DM}^{8}$. In Kinshasa region, Democratic Republic of the Congo (DRC), although there is an existing high overall prevalence of $16 \%$ over the age of 15 years $^{9}$, there is no information on the causes of visual disability among patients with DM. This lack hampers the identification of preventable causes of visual disability in Congolese with DM and the development of programmes for patients with DM. Furthermore, the lack of valid and comparable information renders impossible the monitoring of progress towards St Vincent's targets of reduction of DR-related blindness. Therefore, this study aimed to determine whether diabetic retinopathy remains an independent risk factor of visual disability given the projected aging and the vulnerability of females among Congolese patients with $\mathrm{DM}^{10}$ as well as other primary causes of visual disability ${ }^{6}$. 


\section{Methods \\ Design and setting}

A case-control study was performed on 299 urban patients (108 cases and 191 controls) with type 1 and type 2 DM between April $1^{\text {st }} 2004$ and April $30^{\text {th }}, 2006$. All participants were in Kinshasa town and had a low income. Cases with complete data were selected from all 116 patients with visual disability (response rate:93\%) and consecutively assessed at the Department of Ophthalmology, Teaching Hospital of the University of Kinshasa, serving as a tertiary care center of DRC. Cases were matched to 216 controls for time of admission and type of DM where the 191 controls (response rate: $88 \%$ ) had complete data.

The available information retrospectively obtained from the medical records included demographic data (sex, education level, age) and clinical data such as type of DM, DM duration, presence and duration of arterial hypertension, chronic diabetic complications such as DR, diabetic nephropathy, glaucoma, optic nerve atrophy, visual disability, stages of DR, infections, cataract, agerelated macular degeneration, clinical significant macular edema (CSME), and refractive errors.

\section{Definitions}

Aging was defined by patients with age $\geq 60$ years and across the gradient of Age groups ( $<45$ years; $45-59$ years, $\geq 60$ years). Shorter DM duration was $<5$ years and across DM duration groups $(0-5$ years, 6-10 years, $11-15$ years, $\geq 16$ years).

Clinical data were defined by structured and standardized questionnaires, physical examination and detailed eye examination performed by specialists and reviewed by the Head of the Department. In this study, both the World Health Organization (WHO) definition of visual disability and the Revision of WHO classification (1) were used. Thus, controls had normal vision (VA $1.0-0.3)$ and cases included blindness $(\mathrm{VA}<6 / 60)$, mild and moderate visual impairment (low vision: $\mathrm{VA}<0.3>6 / 60$ ). For the classification of DR, the modified Airlie House classification as introduced by the Early Treatment Diabetic Retinopathy Study (ETDRS) (11) was used as follows: non proliferative (NPDR), proliferative (PDR) and maculopathy. Traditional criteria were used to define the other parameters of interest : arterial hypertension, DM, type 1 and type $2 \mathrm{DM}$, diabetic nephropathy, cataract, age, macular degeneration, refractive errors and glaucoma.

\section{Statistical analysis}

Frequency ( $\%$ ) distributions for categorical variables and means \pm standard deviations for continuous variables were obtained. The contingency table, the proportions and Odds ratio (OR) with 95\% confidence intervals $(95 \% \mathrm{CI})$ were used to assess the univariate association between visual disability, and a number of variables. Multivariate logistic regression analysis was used to assess the independent effect of DR and a given variable on the presence of visual disability after adjusting for the effect of other potential confounders. A $p$ - value $<0.05$ was considered significant. Data analysis was carried out using the Statistical Package for Social Sciences (SPSS) for Windows Version 13 (SPSS Inc, Chicago, IL, USA).

\section{Results}

\section{Characteristics}

Out of 299 participants, 194 (64.9\%) were males and $105(35.1 \%)$ were females. The mean age was $57.8 \pm 10.2$ years (range 21-88 years): 24 were aged less than 45 years $(8 \%), 138$ aged $45-59$ years $(46.2 \%)$ and 137 aged $\geq 60$ years (45.8\%). Type $1 \mathrm{DM}$ was estimated in $32.4 \%$ of patients $(n=79)$ versus type 2 DM estimated in $67.6 \%$ patients $(n=165)$. All participants had no glycemic control: fasting glucose e" $126 \mathrm{mg} / \mathrm{dL}$ and HbA1c e" 10\%. The median duration for DM was 4 years. In this study population, $58.2 \%(\mathrm{n}=174)$ suffered from arterial hypertension; with the median duration of arterial hypertension being 3 years.

\section{Univariate analysis}

Table 1 presents demographic and clinical characteristics in cases and controls. Only older age, low education, presence of DR, and female sex were significantly associated with the presence of visual disability. However, the rest of the variables were not significantly associated with visual disability.

Age $\geq 60$ years conferred almost a double risk for visual disability $(\mathrm{OR}=1.7 ; 95 \% \mathrm{CI} 1-2.9 ; \mathrm{P}=0.043)$. There was a significant $(\mathrm{p}$ for trend $=0.020)$ and positive association between visual disability and aging (figure 1). However, a significant ( $\mathrm{p}$ for trend $=$ 0.000 ) and negative association was shown between $\mathrm{DM}$ duration and visual disability (figure 2). 
Table 1: Comparisons of characteristics of cases with those of controls

\begin{tabular}{llll}
\hline Variables of interest & $\begin{array}{l}\text { Cases of visual dis- } \\
\text { ability } \mathbf{n}(\%) \\
\text { Means } \mathbf{\pm S D} \text { or } \mathbf{n}(\mathbf{~} \%)\end{array}$ & $\begin{array}{l}\text { Controls with } \\
\text { normal vision } \\
\mathbf{n}(\%)\end{array}$ & p- value \\
\hline Age (Years) & $60.1 \pm 10.3$ & $56.5 \pm 9.9$ & 0.003 \\
Low education & $68(62.9)$ & $30(15.7)$ & 0.000 \\
Diabetes duration (years) & $7.6 \pm 7.5$ & $8 \pm 8$ & 0.336 \\
Diabetic retinopathy & $72(66.7)$ & $23(12)$ & 0.000 \\
Females & $66(62.8)$ & $39(37)$ & \\
Diabetic nephropathy & $0(0)$ & $4(2.3)$ & 0.567 \\
Type 1 DM & $42(39)$ & $57(30)$ & 0.200 \\
Type 2 DM & $66(61)$ & $136(71)$ & 0.206 \\
Hypertension & $66(61)$ & $111(58)$ & 0.443 \\
Refractive errors & $4(2.3) 0$ & 0 & 0.567 \\
Cataracts & $36(33)$ & $59(31)$ & 0.236 \\
Glaucoma & $18(17)$ & $34(18)$ & 0.241 \\
CSME & $16(15)$ & $29(15)$ & 0.249 \\
Optic nerve atrophy & $4(2.3)$ & $0(0)$ & 0.567 \\
\hline
\end{tabular}

Figure 1: Relationship between rates of visual disability and aging

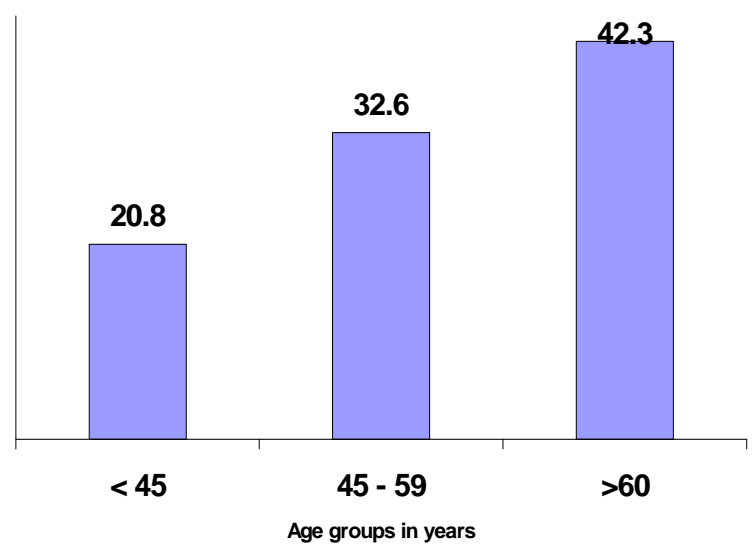

Figure 2: Relationship between visual disability and DM duration groups in years

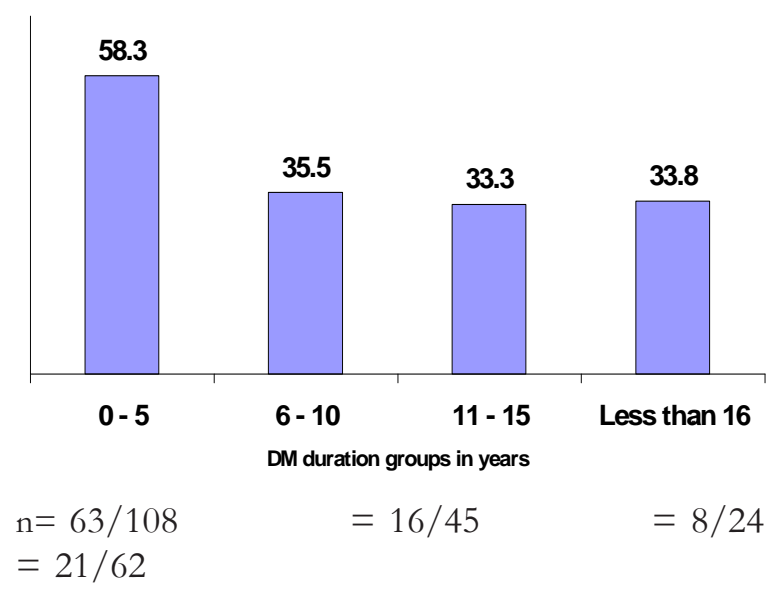

The influence of sex

Female sex conferred a double risk of visual disability in comparison with male sex $(\mathrm{OR}=1.7 ; 95 \% \mathrm{CI}$ 1.02-2.7; $\mathrm{p}=0.028) 95 \% \mathrm{CI} 0.87-2.5 ; \mathrm{p}=0.099)$.

The influence of DR

The DR conferred a triple risk for visual disability $(\mathrm{OR}=2.5 ; 95 \% \mathrm{CI} 1.5-4.1 ; \mathrm{p}=<0.000)$. The risk of visual disability was multiplied by 3 times $(\mathrm{OR}=3$; 95\% CI $1.1-3.4 ; \mathrm{p}<0.050)$ in cases with NPDR when compared with the absence of DR. Compared with NPDR, PDR multiplied by 8 the risk of visual disability $(\mathrm{OR}=8.3$; 95\% CI $1.9-36.9 ; \mathrm{p}=0.000)$. The ratio NPDR/PDR was 1 and 2 among controls and cases of visual disability respectively (figure 3 ).

Figure 3: Distribution of NPDR (in blue) and PDR (in red) in controls and cases of visual disability

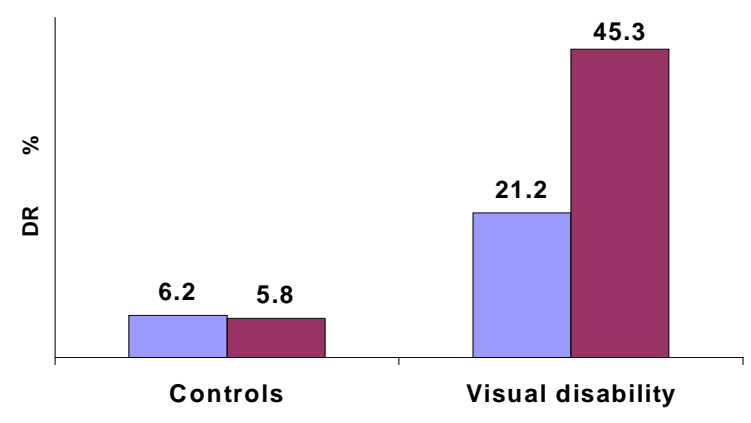
$\mathrm{N}$ of NPDR/PDR
$12 / 191-11 / 191$
$23 / 108-149 / 108$ 
The influence of other ophthalmic disorders and diabetic complications

Vitamin A deficiency, HIV/AIDS, trachoma, macular degenerations, onchocerchiasis, and other infections - related ophthalmic disorders were not reported.

\section{Multivariate analysis}

After adjusting for confounding factors such as aging, diabetic nephropathy, hypertension, low education and DM duration using a logistic regression model, female sex and DR were identified as independent and significant determinants of visual disability in these poor urban patients with DM (table 2).

Table 2: Independent determinants visual disability in Africans with DM

\begin{tabular}{lllll}
\hline $\begin{array}{l}\text { Independent } \\
\text { variables }\end{array}$ & $\mathbf{B}$ & $\begin{array}{l}\text { Standard } \\
\text { Error }\end{array}$ & OR(95\%CI) & P-value \\
\hline Females & 0.750 & 0.382 & $2.1(1-4.5)$ & $<0.05$ \\
DR & 1.458 & 0.430 & $4.3(1.9-10)$ & $<0.001$ \\
Constant & -1.554 & 0.855 & & 0.06 \\
\hline
\end{tabular}

\section{Discussion}

This study identified the risk factors of visual disability among patients with DM in Kinshasa. To our knowledge, these data represent the first assessment of blindness and visual impairment among Congolese patients with DM. These DM patients are at the demographic transition: $46 \%$ with age $\geq$ 60 years. Aging and DM may explain the emergence of arterial hypertension and cardiovascular disease contrary to a commonly held belief of rarity of non-communicable diseases in SSA.

The present study showed that nutrition deficiency - and infections - related ophthalmic disorders are rare, whereas diabetic retinopathy, advanced stages of DR, diabetic nephropathy and macular oedema were common complications of $\mathrm{DM}$ in these Africans. As DM is a mass problem in Kinshasa region', it is urgent to develop programs for early detection and prompt treatment of DM to avoid its serious complications and at least, to delay visual disability.

Our concern in this study was to find a significant univariate association between age, female sex, DR, isolated NPDR, isolated proliferative DR, macular oedema, glaucoma, diabetic nephropathy and visual deficiencies. Other studies showed similar results to our data ${ }^{2,3,5-8,12,13}$. No obvious explanation is provided for relation showed between visual disability and the severity of DR. This means that other factors might be specifically related to DM in SSA and recent high frequency of visual disability in Kinshasa $^{8}$. The possible factors such as poverty, low education attainment, lack of medical insurance, no appropriate diet, lack of Laser, undetected and untreated or poorly controlled diabetes, can result in devastating short-term complications (median DM duration of 4 years) such as visual disability.

The natural history of visual disability in these Congolese patients with DM is partially explained by our findings from logistic regression models. There is an interaction between female sex (genetics) and DR in visual disability onset. It is well established that the uncontrolled DM determines DR and maculopathy ${ }^{13}$. The independent effect of DR on visual disability onset is complex. As sex is a nonmodifiable risk factor for blindness, DR is preventable by early detection and laser treatment ${ }^{14}$. As DR alone is unlikely to be a cause of visual disability without the other assayed ocular complications, other factors such as oxidative/ antioxidative imbalance should be investigated in these patients. Oxidative stress may accelerate DR and visual disability in these young patients with DM and this study may support general and ophthalmic health programs in Africa

\section{Study limitations}

This case-control study is limited to some degree because of its retrospective approach. Patients included in this study and evaluated at a tertiary care center are not representative of all patients with DM in DRC and have more advanced disease.

\section{Conclusion}

The risk of visual disability is higher in females and patients with diabetic retinopathy. This underlines the need to plan regular screening for early detection and timely laser treatment of diabetic retinopathy among these urban uncontrolled and poor patients with DM. 


\section{Acknowledgments}

We thank LOMO Medical Clinic, Kinshasa, DRC for the financial support.

\section{References}

1. Dandona L, Dandona R. Revision of visual impairment definitions in the International Statistical Classification of Diseases. BMCMedicine 2006;4:7 doi:10.1186/1741-7015-4-7.

2. Evans j. Causes of blindness and partial sight in England and Wales 1990-1991. London:HMSO, 1995.

3. Kumar N, Goyder E, McKibbin M. The incidence of visual impairment due to diabetic retinopathy in Leeds. Eye 2006;20:455-459.

4. Centers for Disease Control and prevention (CDC). Prevalence of visual impairment and selected eye diseases among persons aged e"50 years with and without diabetes-United States, 2002. MMWR Morb Mortal Wkly rep 2004; 53:1069-1071.

5. Maha I Al-Till, Mouawyah D Al-Bdour, Kamel M Ajlouni. Prevalence of blindness and visual impairment among Jordanian diabetics. Eur J Ophtalmol 2005;15:62-68.

6. Cotter SA, Varma R, Ying-Lai, Azen SP, Klein R. Causes of low vision and blindness in adult Latinos: the Los Angeles Latino Eye Study. Ophthalmology 2006; 113:1574-1582.

7. Schemann JF, Inocencio F, de Lourdes Monteiro M, Andrade J, Auzemery A, Guelfi Y. Blindness and low vision in Cape verde Islands : results of a national eye survey. Ophthalmic Epidemiol 2006; 13: 219-226.
8. Mvitu M, Kimenyembo W, Kaimbo wa Kaimbo D, Driven W, Muls E. Frequency of visual impairment and blindness in Congolese people with diabetes. Mali Med 2009; 3: 22-26.

9. Longo-Mbenza B, Vangu Ngoma D, Nahimana $\mathrm{D}$, et al. Screen detection and the who stepwise approach to the prevalence and risk factors of arterial hypertension in Kinshasa. EurJ Cardiovasc Prev Rehabil 2008; 15:503-508.

10. Longo-Mbenza B, Nkondi Mbadi A Nsungu J, Mbungu Fuele S. Higher pulse pressure. Systolic arterial hypertension, duration of diabetes and family history of diabetes in Central Africans. International Journal of Diabetes \& Metabolism 2008; 16:17-23.

11. Early treatment diabetic retinopathy study research group. etdrs Report number 7. Ophthalmology, 1991; (Suppl 5), 98: 741-56.

12. Sjolie AK, Stephenson J, Aldington $S$ et al. Retinopathy and vision loss in insulin dependent diabetes in Europe. The EURODIAB IDDM complications study. Ophthalmology 1997; 104: 252-260.

13. Henricsson M, Tyrberg M, Heijl A, Janzon L. Incidence of blindness and visual impairment in diabetic patients participating in an Ophthalmological control and screen in program. Acta Ophthalmol Scand 1996; 74: 533538.

14. United Kingdom prospective diabetes study group: Intensive blood glucose control with sulphnylureas treatment and risk of complications in patients with type 2 diabetes. UKPDS 33. Lancet 1998; 352: 837-853. 